\title{
Fruiting of macromycetes in artificial plantations of Pinus sylvestris $L$. on the waste dump of the Kedrovsky open-cast coal mine
}

\author{
Olga Legoshchina* \\ Federal Research Center of Coal and Coal Chemistry SB RAS, 10 Leningradsky Ave, Kemerovo, \\ 650065, Russia
}

\begin{abstract}
The quantitative registration of macromycete fruiting bodies was performed during two field seasons in the pine plantations of recultivated waste dump (experimental area) and in the pine forests on zonal soils (control area). The average quantity of carpophore macromycetes on the experimental area during two years of research exceeded ones on the control area by $41 \%$. The field season of 2020 was characterized by significantly increased productivity of fungi in the studied areas; two peaks of mass fruiting of macromycetes were registrate. The maximum frequency of fruiting bodies of higher fungi was discovered in the autumn peak of mass fruiting mediated mainly by fair appearance of symbiotrophic fungi. Both studied areas in the different years of research were characterized by oppositely processes providing the distribution of carpophore macromycetes in pine plantations with different crown density (sparse, medium and dense). Taking into account the crown projection zones, the maximum frequency of macromycete fruiting bodies was located in the near-crown and outer zones of Pinus sylvestris L. trees.
\end{abstract}

\section{Introduction}

Kuzbass is a region with a number of environmental issues due to a large-scale coal mining. Coal production is growing every year mainly due to open-cast mining. In 2018 and 2019, 255.3 and 250.1 million tons of coal were mined, respectively. During coal mining, natural biogeocenoses with their biodiversity can be completely destroyed. According to appraisal, the area of disturbed territories in Kuzbass is 120-150 thousand hectares [1]. Forest recultivation is the leading technology resulting to restoration of territories disturbed during coal-mining. The formed technogenic landscapes become "ecoclines" with characteristics that are radically different from former natural ecosystems. Finally, post-technogenic landscapes restoration leads to the creation of stable and sufficiently productive ecosystems with high biodiversity [2]. Studying how the individual components of technologically disturbed territories (flora, fauna and mycobiota) are functioning is a priority in modern environmental research.

${ }^{*}$ Corresponding author: legoshchina@mail.ru 
Not only a fully-developed vegetation cover but also a well-coordinated system of decomposers including mycobiota is the significant indicator of restoration of territories disturbed during coal-mining. Fungi are the main link in the heterotrophic part of ecosystem; they perform destruction of plant residues and the recurrence of organic matter to ecosystem. Higher fungi can form nitrogen environment in symbiosis with plants, which ensures the cenosis functioning in the conditions of sharp nutrients deficiency. Moreover, fungi contribute to the biochemical destruction of lithogenic substrates that is necessary to accumulate a sufficient amount of physical clay fractions and, generally, to the soilecological effect [3].

Mycocenosis on recultivated territories are studied not long ago and macromycetes on post-technogenic territories are poorly investigated [4-6]. Thus, this research was aimed to study the features of fruiting macromycetes in artifical plantations Pinus sylvestris L. on the waste dump of Kedrovsky open-cast mine.

\section{Materials and Methods}

The presented study was performed from 2019 to 2020; the experimental area was located $25 \mathrm{~km}$ north-east of Kemerovo on the waste dump of open-cast mine belong to OAO "UK Kuzbassrazrezugol". According to the ecological-geographical zoning, the Kedrovsky open-cast coal mine is placed in the northern forest-steppe of the Kuznetsk depression [7]. The study objects are the permanent experimental plots in pine plantations on the planned waste dump of the Kedrovsky open-cast coal mine without applying a fertile or potentially fertile soil.

To identify different conditions compared to natural landscapes we selected areas without applying soil improvers - the root-inhabited horizon is composed of heterogeneous mass of sedimentary rocks (sandstones and siltstones) with some inclusion of igneous rocks and loess-like loams. According to the previously obtained taxation data [8], the age of plantations in 2019 was 29 years (II class of age).

Pine plantations growing on the zonal meadow-chernozem soils of the Kuzbass Botanical Garden (Kemerovo) were selected as the control area due to the lack of zonal pine forests characterized by a similar age and crown density in Kemerovo, which requires the methodology of this research.

On the experimental and control areas, three plots according to the visual gradation of the crown density were selected: 1UP - sparse stands (open stands) with 20-30\% crown closure; $2 \mathrm{UP}$ - medium-closed stands with 50-60\% crown closure and 3UP - dense stands with $80-90 \%$ crown closure. On each plot, under-crown and near-crown (inter-crown) zones, as well as outer zones in sparse stands, were established according to the main parameters of ground cover [9].

Field work was performed during the summer-autumn period (from June to September). Fruiting bodies (carpophores) were counted every seven days. Macromycetes was determined by basidiomes in the field and in the laboratory [10]. The Latin names of fungi and their systematic position are given according to the Index Fungorum electronic database.

\section{Results and Discussion}

As a result of the macromycete counting on the studied areas, a significantly increased frequency of carpophores in the pine stands growing on the waste dump of the Kedrovsky open-cast coal mine was discovered. The average quantity of carpophore macromycetes on 
the experimental area during two years of research exceeded ones on the control area by $41 \%$. The most expressed differences in the frequency of fungi in the studied areas were observed in 2020. The sudden change in the frequency of fungi from August 30 to September 28 can be explained by the intense fruiting of symbiotrophic macromycetes [Suillus luteus (L.) Roussel, Tricholoma albobrunneum (Pers.) P. Kumm., Thelephora caryophyllea (Schaeff.) Pers.]. At the same time, fungi productivity in the pine forests growing on the waste dump was 55\% higher compared to the control areas (Fig.). V.I. Shubin [11] reported that fruiting bodies of symbiotrophic macromycetes and fungal mycelium play the important role in forest ecosystems consisting in the storing of biogenic elements in the root-inhabited soil horizon. Thus, we suggested that high productivity of symbiotrophic macromycetes on the experimental area discovered in the presented research can have a protective mechanism preventing the loss of deficient nutrients (in particular, labile nitrogen) from the upper part of technogenic eluvium in the waste dump.

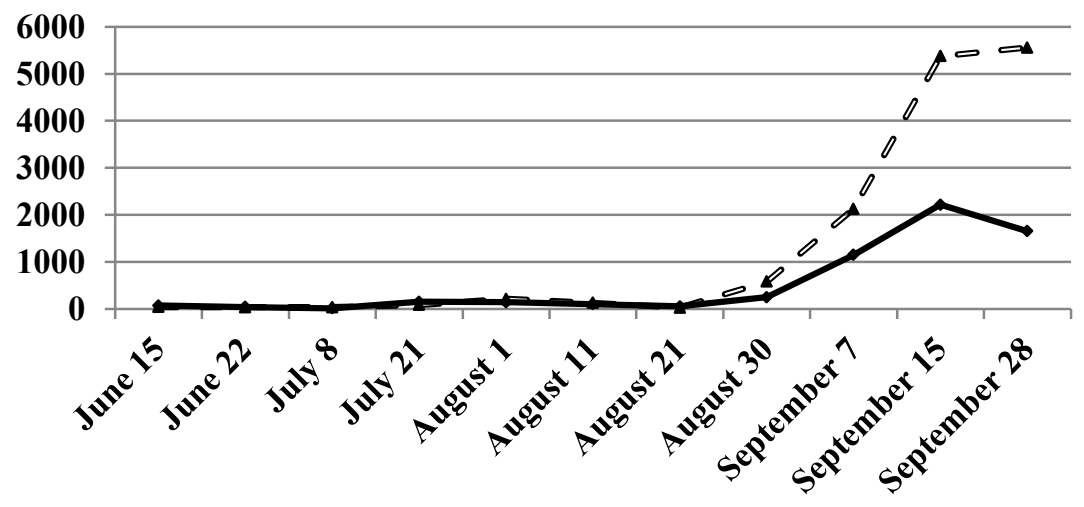

$\longrightarrow$ Kuzbass Botanical Garden

$\triangle \leftrightarrow$ Kedrovsky open-cast mine

Fig.Dynamics of macromycetes frequency on the studied areas during the summer-autumn period 2020.

In 2020, two peaks of fruiting were identified. The first smoothed peak of the mass fruiting of fungi in the pine plantations of the experimental area was registered in the middle of summer (from July 21 to August 1). The period from August 30 to September 28 was corresponded to the second peak of mass fruiting of macromycetes and it was more expressed. According to the meteorological report, July 2020 was the warmest summer month with the most level of atmospheric precipitation (153-227 \% of the normal amount) [12]. It is known that the circadian rhythms in fungi are determined both by their biological characteristics and climatic factors of the environment including such import ones as temperature and moisture of the soil. Therefore, warm weather in July and heavy precipitations are favorable to the mass fruiting of macromycetes from late July to early August.

We discovered that the distribution of carpophores of higher fungi in pine stands with different crown density was varied in the years while the study was performing (Table.). In 2019 , the number of fruiting bodies of macromycetes on the experimental and control areas was significantly exceeded in sparse (1UP) and medium-closed (2UP) stands. At the same time, in the pine forest growing on the waste dump, the frequency of carpophores from 1UP and 2UP was significantly increased compared to $3 \mathrm{UP}$ by $54 \%$ and $55 \%$, respectively. In 
2020, an opposite pattern was observed: the massive fruiting of macromycetes was discovered in dense pine stands. It was suggested that the fruiting of symbiotrophic macromycetes depends on crown dense and can be decreased in dense stands [11].

The results obtained in 2020 are different from the available literature. Apparently, twoyears monitoring of the fruiting of higher fungi is insufficient to the complete understanding of the mechanisms occurring in mycocenosis from pine plantations, so the subsequent study for several more years is necessary.

Table. The number of carpophore macromycetes on the studied areas from 2019 to 2020 taking into account crown density

\begin{tabular}{|c|c|c|c|c|}
\hline \multirow{2}{*}{$\begin{array}{c}\text { Crown } \\
\text { density }\end{array}$} & \multicolumn{2}{|c|}{$\begin{array}{c}\text { Kedrovsky open-cast mine } \\
\text { (experimental area) }\end{array}$} & \multicolumn{2}{c|}{$\begin{array}{c}\text { Kuzbass Botanical Garden } \\
\text { (control area) }\end{array}$} \\
\cline { 2 - 5 } & \multicolumn{4}{|c|}{ Frequency of carpophores, N } \\
\hline Sparse & 2019 & 2020 & 2019 & 2020 \\
\hline Medium & 2967 & 4251 & 1797 & 1826 \\
\hline Dense & 1329 & 4308 & 3663 & 1689 \\
\hline
\end{tabular}

The study of the pattern of macromycete fruiting bodies in the crown projection zone showed a tendency to increase the frequency of fungi from a tree trunk to its periphery. The near-crown and outer-crown zones of crown projection are characterized by an increased number of macromycete fungi carpophores. According to the two-year monitoring, the average quantity of fungi in artificial pine plantations on the waste dump of open-cast mine in the near-crown and outer-crown zones was $82-87 \%$ and $87 \%$ higher compared to the under-crown zone (located near the tree trunk) of pine stands with different crown density. The differences in fungi fruiting on the experimental area between the under-crown and the near-crown zones, as well as between the under-crown and outer-crown zones discovered in 2020 were more pronounced (86-92\% and $92 \%$, respectively). We supposed that the abundant fruiting of macromycetes in the near-crown zone is stipulated for increased moisture of substrate, which is confirmed by the presence of a moss cover on the forest floor of this zone [9].

\section{Conclusion}

The pine plantations growing on the waste dump of the Kedrovsky open-cast coal mine are characterized by the highest productivity of higher fungi. The "splash" of species diversity of macromycetes was more pronounced on the waste dumps compared to zonal soils and it can be a mechanism of technogenic substrates transforming. So we can suggest that Pinus sylvestris L. can play a positive role as an edifier of technogenic forest ecosystems at the initial stage of their functioning. Resulting on the formation of heterogeneous environmental conditions under and outside the crown of trees, irregular distribution of macromycetes depends on the crown of woody plants was observed. The quantity of carpophores of higher fungi increases from the tree trunk to the outer-crown zone, while the near-crown and outer-crown projection zones are characterized by the highest productivity of macromycete fungi. We concluded those two years of field observation are insufficient to understand the mechanisms of the functioning of mycocenoses in pine stands of post- 
technogenic landscapes. Long-term mycological monitoring is important for understanding the correlation between fungal growth and various environmental factors.

The work was carried out within the framework of the state assignment of the Federal Research Center of Coal and Coal Chemistry SB RAS (project no. 0286-2021-0010).

\section{References}

1. V.I. Ufimtsev, Yu.A. Manakov, A.N. Kupriyanov, Methodical recommendations for forest reclamation of disturbed lands at coal industry enterprises in Kuzbass (Irbis, Kemerovo, 2017)

2. GOST R 57446-2017. Best available technology. Reclamation of disturbed lands and land plots. Restoration of biological diversity (Standardinform, Moscow, 2017)

3. V.A. Androkhanov, E.D. Kulyapina, V.M. Kurachev, Soils of technogenic landscapes: genesis and evolution (Publishing house of SB RAS, Novosibirsk, 2004)

4. M.A. Safonov, A.A. Cherdintsev, A.S. Malenkova, et al., Fund. Res., 1:78-82 (2014)

5. O.E. Kryuchkova, Izv. RAN. Biol. series., 2, 203-208 (2014)

6. A.S. Shishikin, D.Yu. Efimov, R.T. Murzakmatov, Sib. For. J., 5, 109-117 (2019)

7. Ecological map of the Kemerovo region (Federal Service of Geodesy and Cartography of Russia, Moscow, 1995)

8. V.I. Ufimtsev, I.P. Belanov, Sib. For. J., 6, 56-68 (2018)

9. E.Yu. Kolmogorova, V.I. Ufimtsev, Adv. In Cur. Nat. Sci., 11(2), 267-272 (2018)

10. M.A. Bondartseva, Keys to mushrooms of Russia. Order aphyllophoric (Nauka, St. Petersburg, 1992)

11. V.I. Shubin, Fung. Com. In For. Ecosyst., 2, 272-286 (2004)

12. Report on the state and protection of the environment of the Kemerovo region - Kuzbass in 2020 (Ministry of Natural Resources and Ecology of Kuzbass, Kemerovo, 2021) 